\title{
Introdução - Para além dos trópicos e dos consensos: atores, práticas e questões na história dos parques e jardins no Brasil ${ }^{1}$
}

Introduction - Beyond tropics and consensus: social actors, practices and challenges in the history of parks and gardens in Brazil

\section{PAULO CÉSAR GARCEZ MARINS²}

Universidade de São Paulo / São Paulo, SP, Brasil

\author{
MÔNICA RAISA SCHPUN ${ }^{3}$ \\ Ecole des hautes études en sciences sociales / Paris, France
}

Entre 2012 e 2016, o Brasil teve dois de seus mais importantes marcos urbanos reconhecidos como patrimônio mundial pela Unesco. No Rio de Janeiro, essa honra recaiu sobre as "paisagens cariocas, entre o mar e a montanha" e, em Belo Horizonte, sobre o conjunto moderno de Pampulha. No primeiro deles, o perímetro de proteção abrangeu as montanhas cobertas de florestas tropicais do Parque Nacional da Tijuca, os famosos picos de granito do Corcovado e do Pão de Açúcar e parques como o Jardim Botânico, o Passeio Público e os jardins do Aterro do Flamengo. Na capital de Minas Gerais, a nominação incluiu os edifícios de Oscar Niemeyer que pontuam a lagoa da Pampulha, entre os quais se destaca a igreja de São Francisco de Assis e sua curvilínea silhueta, criações que deram a esse arquiteto brasileiro o início de seu reconhecimento internacional. Mas essas duas decisões da Unesco também constituem, em seus textos justificativos, uma homenagem explícita ao mais famoso paisagista brasileiro: Roberto Burle Marx ( $1909-1$ 994). São de sua concepção a maior parte dos jardins da Pampulha, bem
1. A concepção desse dossiê - publicado em português por Anais do Museu Paulista e em francês por Brésil(s). Sciences bumaines et sociales - originou-se de reflexões vinculadas ao projeto internacional "Do mundo em miniatura ao jardim planetário: imaginar, viver e (re)criar o jardim, dos mundos antigos aos nosso dias", sediado na Universidade Sorbonne Paris Cité (USPC), reunindo pesquisadores da École des hautes études en sciences sociales (EHESS), da l'École nationale supérieure d'architecture de $\mathrm{Pa}$ ris-Val de Seine, da Universidade de São Paulo (USP), da Universidade Estadual de Campinas (Unicamp) e da Universidade do Estado do Rio de Janeiro (UERJ).

2. Historiador, docente e membro da esquipe curatorial do Museu Paulista da Universidade de São Paulo (USP), docente dos Programas de Pós-Graduação em Museologia e em Arquitetura e Urbanismo da USP; editor de Anais do Museu Paulista: História e Cultura Material. 
3. Historiadora, pesquisadora do Centre de recherches sur le Brésil colonial et contemporain de l'École des hautes études en sciences sociales (CRBC/Mondes américains - EHESS, Paris) e professora-visitante na FAUUSP (2017-2020); editora de Brésil(s). Sciences bumaines et sociales.

4. Ver, por exemplo, no que tange a São Paulo, o estudo de Vladimir Bartalini (1999). como os do Aterro do Flamengo e aqueles ao longo da praia de Copacabana, esses últimos ornados com mosaicos de pedra portuguesa igualmente desenhados pelo paisagista.

Burle Marx começou a obter seu reconhecimento internacional a partir da década de 1940. Foi nessa época que o Museu de Arte Moderna de Nova York (MoMA) exibiu projetos seus pela primeira vez, que passaram também a ser publicados regularmente nas páginas de revistas especializadas europeias e norteamericanas. A criação de novas linguagens artísticas modernas e a utilização de plantas tropicais em projetos de Burle Marx garantiram a presença de parques e jardins brasileiros em livros de referência sobre design paisagístico do século XX. As homenagens agora realizadas pela Unesco podem ser consideradas o ponto culminante desse processo de consagração internacional.

Mas para além das criações do mestre do paisagismo brasileiro do século $X X$, pode-se dizer que muitos outros parques considerados bens patrimoniais no Brasil - alguns deles datando dos séculos XVIII e XIX - são simultaneamente tema de interesse para pesquisadores, para gestores da esfera pública e para os cidadãos. Patrimônio multifacetado, esses espaços, que vêm atuando há séculos como mediadores da sociabilidade urbana, merecem mais atenção. Eles acolheram espécies de plantas de todos os continentes e permitiram experiências de criação artística e práticas inovadoras alcançadas por meio de sínteses realizadas por paisagistas, por jardineiros e por artesãos dedicados à sua ornamentação. Essas práticas paisagísticas, amplas e diversificadas, foram eclipsadas por aquelas advindas dos jardins tropicais criados por Burle Marx ou por seus discípulos, associados ao movimento moderno de arquitetura e de paisagismo. E, com efeito, a compreensão desse importante patrimônio cultural permaneceu, quase sempre, limitado principalmente aos aspectos relativos à sua concepção formal.

Pouco estudados pelas ciências humanas e sociais no Brasil, os parques e jardins de suas cidades são, no entanto, um objeto particularmente rico para quem está interessado nos modos de conceber, organizar, frequentar e preservar o espaço público. ${ }^{4}$ Além disso, seu exame também permite iluminar questões e conflitos sociais, políticos e simbólicos. Esses locais, verdadeiros laboratórios de relações da sociedade, atravessam a história do urbanismo, do paisagismo e das políticas de definição e preservação do patrimônio cultural em nível local, regional ou nacional, bem como a própria história social das cidades. Tal temática também abrange o estudo da flora - que é selecionada, organizada e também revisitada para a composição e o desenho de um parque ou jardim - o que, no Brasil, ainda a relaciona ao imaginário dos trópicos e sua problematização. A escala, a 
preservação e a utilização dos espaços verdes das cidades brasileiras são, por fim, indicadores indispensáveis das condições da vida urbana. E se sua configuração atual nos interessa, tal se dá por relacionarem-se a uma história complexa, em que os mais diversos interesses econômicos e políticos ali convergem e se encontram. Tais lugares podem, portanto, tornarem-se ícones, dimensão que muito diz sobre o país, sobre as cidades e sobre a história que os moldaram. Tratase, ao fim e ao cabo, de espaços-chave que, situados no centro das cidades e da vida urbana, viabilizam os encontros, o viver coletivo, o aprendizado tanto dos convívios quanto das exclusões, do reconhecimento entre os iguais e da experiência das desigualdades. ${ }^{5}$ E constituem, sempre, referências centrais no mapa mental dos habitantes de uma cidade.

Inscritos na paisagem urbana brasileira desde o período colonial, os parques e os jardins remetem, assim, às tradições luso-tropicais de agenciamento desses espaços. $\bigcirc$ Passeio Público do Rio de Janeiro, criado na década de 1780, foi inspirado em jardins geométricos franceses, modelo que foi reinterpretado em Portugal e em seu mundo colonial. Ele é o exemplo mais conhecido do surgimento desses novos espaços urbanos brasileiros que, durante a segunda metade do século do século XVIII, associavam referências formais vindas da Europa ao cultivo de plantas nativas da América ou das Índias Orientais. ${ }^{6}$ Nesse sentido, tais espaços foram laboratórios em que se reformulou a arte dos jardins vinda da Europa, favorecendo não apenas a reinvenção morfológica, mas também a seleção e adaptação de múltiplas espécies aos diferentes climas do Brasil. Essa aliança entre organização espacial e aclimatação vegetal marcou os jardins de numerosas cidades do país ao longo do século XIX.

Os parques e jardins franceses de estilo paysager concebidos e construídos em Paris durante o Segundo Império, de imensa repercussão internacional, constituíram outra referência para o paisagismo brasileiro, o que favoreceu a instalação de profissionais franceses em diversas cidades do país. $\bigcirc$ percurso profissional e a produção de Auguste Glaziou (1828-1906), o mais conhecido mediador dessas práticas paisagísticas entre a França e o império brasileiro, vem sendo tema de estudos recentes dedicados à compreensão de seu modo de trabalho e das soluções assumidas por ele em suas criações. ${ }^{7}$ Seus discípulos frequentemente conciliaram a evocação do pitoresco, a técnica das rocailles (falseamento de pedras e troncos) e os traçados naturalistas característicos do estilo paysager com as aleias neoclássicas de palmeiras imperiais (Roystonea oleracea). Assim, Glaziou e seus seguidores realizaram sínteses audaciosas entre repertórios formais que se oporiam na Europa, fazendo com que o Brasil se tornasse berço dessas novas sínteses criativas. A reflexão sobre o paisagismo aqui se dava por meio das práticas, realizadas por agentes de origens diversas, cujas obras, muito
5. Ver David Scobey (1992) e Elijah Anderson (2011, p. 104-150).

6. Ver Hugo Segawa (1996).

7. Ver Jean-Pierre Bériac (2012) e Carlos G. Terra (2000 e 2015). 
8. Ver Guilherme Massa Dourado (2011). embora fossem inspiradas em ideias e técnicas em voga na Europa, eram marcadas por especificidades locais.

Na virada para o século XX, a urbanização massiva ocorrida nas grandes cidades brasileiras - impulsionada pelas vagas de imigrantes e pelas intervenções urbanísticas ocorridas nas capitais por determinação das novas autoridades republicanas - reforçou a importância dos jardins e dos parques. Movidos por um imaginário europeizante, no mais das vezes afrancesado, os governantes multiplicaram as encomendas. Iniciativas de melhoramento e embelezamento foram facilitadas pela presença de artesãos qualificados em inúmeras especialidades, a maioria deles imigrantes, contratados tanto pelas autoridades públicas quanto pelas elites urbanas possuidoras de palacetes cercados de imponentes jardins privados.

Parques e jardins tornaram-se, então, verdadeiros cenários a céu aberto, que permitiam a exibição dos corpos de mulheres e homens de elite, a realização de práticas de lazer pelas camadas populares, bem como a percepção recíproca das diferenças sociais devidas tanto à emergência das classes médias quanto à própria complexificação da composição social. Espaços civilizacionais dos cidadãos por excelência, os jardins foram também lugares em que floresceram os equipamentos arquitetônicos e soluções paisagísticas característicos da Belle Époque: coretos para apresentações musicais, pavilhões, pérgulas, espelhos d'água, fontes e chafarizes, monumentos, bustos, esculturas e elementos decorativos variados, além de aleias e canteiros dos mais diversos tipos. ${ }^{8}$

Entretanto, conhecemos ainda muito pouco sobre a produção paisagística da Belle Époque brasileira. Os preconceitos interpretativos sobre tal produção, herdados do modernismo, estabeleceram uma barreira poderosa e longeva que desfavoreceram o seu estudo. Os idealizadores, artesãos e demais profissionais que a realizaram e mantiveram esses espaços são sempre ignorados. Tomados até muito recentemente como simples cópias sem grande interesse de modelos europeus, os jardins [e parques] da Primeira República começaram, a duras penas, a serem vistos como expressões efetivas de releituras locais em relação a seus referenciais. A retomada dos princípios paisagísticos herdados de Le Nôtre que caracterizou o paisagismo corrente nas principais cidades brasileiras a partir da década de 1900 - e que ali se deu quase simultaneamente ao que também ocorria na França conectou tais cidades aos circuitos mundiais de difusão e de reelaboração desses princípios. Paisagistas franceses aqui estabelecidos foram promotores de tal fenômeno, sendo numerosos tanto no Brasil quanto em outros países latinoamericanos como a Argentina e o Uruguai, bem como no Ultramar francês.

Esse quadro foi transformado radicalmente a partir da década de 1930, quando a arquitetura moderna se aproximou das formas concebidas por Burle Marx 
para seus jardins brasileiros. Esse paisagista revolucionou as associações entre as floras nativa e exótica, bem como as relações entre espécies vegetais e os elementos arquitetônicos, em negação radical das referências historicistas correntes nas décadas anteriores. Autor de projetos que contribuíram de modo significativo para a configuração das identidades urbanas do Rio de Janeiro, São Paulo e Brasília, entre outras cidades brasileiras, tanto quanto de obras icônicas do paisagismo de cidades [estrangeiras], tropicais e subtropicais, como Caracas, Kuala Lumpur ou Miami, Burle Marx é incontestavelmente o grande nome do paisagismo brasileiro do século XX. E esse protagonismo vem sendo reconfirmado no presente graças a exposições realizadas no Brasil, nos Estados Unidos e na Europa. ${ }^{9}$

A notoriedade incontornável de Burle Marx acabou, entretanto, por eclipsar uma produção variada tanto de parques e jardins que se vinculavam e reinterpretavam as correntes paysagère e historicistas, quanto aos muitos outros que se inseriam nos princípios modernistas ou pós-modernos. Essas realizações paisagísticas vêm, contudo, sendo(re)conhecidas, de maneira cada vez mais sistemática, graças a pesquisadores prontos a documentar produções e percursos profissionais para além das armadilhas conceituais estabelecidas pela tradição interpretativa modernista. ${ }^{10}$

Essas complexas intervenções urbanas de caráter paisagístico tornaram-se tardiamente um objeto de atenção por parte dos órgãos responsáveis pela preservação e valorização do patrimônio cultural. Frequentemente negligenciadas e, por vezes, destruídas - como foi o caso dos parques do centro da cidade de São Paulo concebidos pelo francês Joseph-Antoine Bouvard (1840-1920) - tais obras paisagísticas sofreram as consequências das tensões entre os interesses públicos e privados (sob o pano de fundo da especulação imobiliária), bem como daquelas que privilegiaram a expansão de avenidas em detrimento da expansão ou da preservação dos espaços verdes.

Essas contradições, se se mostram particularmente agudas hoje em dia, não são, no entanto, recentes e menos ainda exclusivas da contemporaneidade. Pelo contrário, estão enraizados em uma longa história de conluio entre os interesses privados e a ação das autoridades públicas nas cidades brasileiras, especialmente no que se refere à propriedade e à especulação da terra. Os processos de urbanização, frequentemente violentos e sem planejamento, são responsáveis pelo limitado espaço disponível para os jardins [e parques] urbanos e também por seu abandono devido à sua falta de rentabilidade.

Este dossiê, sem pretender ser exaustivo, volta-se a momentos marcantes da história dos parques e jardins no espaço público brasileiro. Os artigos que o compõe se atém a temas, atores, práticas sociais e conflitos políticos que
9. Ver Lauro Cavalcanti e Farés El-Dahdah (2009); Lauro Calvalcanti, Farés El-Dahdah e Francis Rambert (2011) e Jens Hoffmann e Claudia J. Nahson (2016). Essas três publicações foram editadas por ocasião de exposições dedicadas a Burle Marx. A primeira delas, realizada no Paço Imperial do Rio de Janeiro e no Museu de Arte Moderna de São Paulo (MAM-SP) e denominada Roberto Burle Marx 100 anos - a permanência do instável, foi posteriormente reapresentada na Cité de l'architecture et du patrimoine em Paris. A segunda exposição, denominada Roberto Burle-Marx: A Brazilian Modernist, foi exibida em 2016 no Jewish Museum de Nova York (2016) e, posteriormente, no Deutsche Bank Kunst Halle em Berlin.

10. Ver, por exemplo, os trabalhos de Silvio Soares Macedo (1999 e 2012); Silvio Soares Macedo e Francine Gramacho Sakata (2002) e de Fabio Robba e Silvio Soares Macedo (2002), todos oriundos do projeto de pesquisa Quapá (Quadro do Paisagismo no Brasil, realizado na FAU-USP). 
caracterizaram esses espaços ao longo de sua trajetória. Várias são as abordagens utilizadas, capazes de configurar não apenas a riqueza temática proporcionada pelo objeto proposto, mas de trazer à tona aspectos que the são comuns.

Cristiane Maria Magalhães volta-se a uma técnica ornamental utilizada ao longo do século XIX e princípios do século XX - a rocaille - bem como aos artesãos que a dominavam e difundiam. Concentrando-se especialmente no Sudeste brasileiro, a autora reconstitui os percursos de dois dos rocailleurs mais importantes do período - o francês Paul Villon e o português Francisco da Silva Reis. Almejando mimetizar a natureza, as rocailles geralmente imitavam a textura de troncos de árvores e de pedras por meio do uso de cimento. Elas podiam ser encontras sob múltiplos formatos, tanto em ornamentos quanto em equipamentos habitualmente presentes nos jardins em estilo paysager: pontes, bordas de lagos e espelhos d'água, cascatas e grutas artificiais, mirantes, coretos e pavilhões, bancos de jardim, mesas, refúgios... E, segundo o gosto da época, as rocailles não eram exclusivas de espaços públicos, pois famílias abastadas as utilizaram tanto em jardins de suas residências urbanas quanto em fazendas. Apesar da sua disseminação, a moda das rocailles não deixou muitas pistas fáceis para sua documentação, haja visto, por exemplo, a raridade de assinaturas de seus artífices inscritas em suas criações. Muitas das obras desapareceram com a chegada, logo após sua voga, do paradigma estabelecido pela arquitetura moderna, também adotado pelo paisagismo e pelo urbanismo brasileiros de então. A autora deste artigo mobilizou diversas fontes para identificar as obras remanescentes, bem como para reconstituir o savoir-faire dos técnicos especializados em rocailles [- chamados por vezes de cascateiros -] que, numa época de grandes intervenções urbanas, trabalharam primeiramente no Rio de Janeiro e em seguida em muitas outras cidades do país.

Aline de Figuerôa Silva leva-nos aos jardins de Fortaleza, no Nordeste do Brasil, na passagem dos séculos XIX e XX. Examina as relações que ali se davam entre as características atribuídas à flora natural e as da vegetação dos jardins públicos desta cidade quente e árida. $\bigcirc$ imaginário que privilegia os jardins exuberantes do trópico úmido, considerados uma marca de brasilidade, é ali contrariada. A autora volta-se às técnicas desenvolvidas para superar o problema [da aridez]. O cerne do artigo refere-se à escolha das espécies arbóreas plantadas nos espaços examinados e às soluções hídricas utilizadas para combater os efeitos da insolação excessiva e a crônica falta d'água [que assola] a cidade. Ela se detém na implantação de lagos artificiais com finalidades utilitárias le não decorativas) e, sobretudo, na instalação de cata-ventos de fabricação estadunidense visando ao bombeamento de águas subterrâneas e sua estocagem em reservatórios 
metálicos. Desaparecidos a partir da década de 1930, esses equipamentos permanecem, contudo, registrados em diversas fontes documentais, escritas e iconográficas. Tais cata-ventos instalados em jardins foram uma singularidade de Fortaleza no âmbito dos jardins urbanos brasileiros.

Os outros três artigos referem-se a jardins marcados pelos princípios de arte e da arquitetura modernas brasileiras, em que a produção de Roberto Burle Marx se impôs com maestria. Vera Beatriz Siqueira detém-se na maneira como o paisagista utilizou elementos arquitetônicos, recolhidos entre os destroços das demolições de imóveis cariocas erguidos no século XIX e primeiras décadas do século XX, para criar composições inusitadas em meio ao seu jardim privado - o Sítio Santo Antônio da Bica, atualmente denominado Sítio Roberto Burle Marx, no Rio de Janeiro. A autora constata uma conexão entre essas práticas de composição a ele específicas e aquelas de colecionador de plantas e objetos de arte que Burle Marx também foi. Segundo Siqueira, ao levar-se em conta a "tradicional [perspectiva] da história do modernismo brasileiro" essas intervenções poderiam ser qualificadas de conservadoras, ou até mesmo de "regressivas". Sua análise permite, porém, construir novas ferramentas críticas para reler a obra do paisagista. Ao preservar e valorizar esses vestígios arquitetônicos do século XIX e da Belle Époque, Burle Marx contrariou a tendência de menosprezar tais testemunhos praticado por seus colegas, embevecidos que estavam pelo modernismo. Considerado um ícone de sua geração - quando vivo e também depois que partiu - vê-se aqui, contudo, que ele não seguia cartilhas.

Trabalhando o contexto paulista, Fernanda Araujo Curi se interessa, por seu lado, pela longa história de relações particularmente complexas entre Burle Marx e o Parque Ibirapuera, o mais importante espaço paisagístico de São Paulo, inaugurado em 1954 por ocasião do quarto centenário da cidade. Enquanto a maior parte das numerosas construções ali erguidas levam a assinatura de Oscar Niemeyer e de sua equipe, o projeto inicial dos jardins foi concebido por Burle Marx. Esse projeto, no entanto, jamais se efetivou. Apesar disso, paisagista foi ainda o autor de dois outros projetos para o Parque, realizados nas décadas de 1970 e 1990 e somente o último deles foi realizado, ainda que parcialmente. Fernanda Curi examina, ao longo dessa trajetória, as resistências impostas à implantação de cada um desses projetos de Burle Marx. Para tanto, a autora percorre as veredas de uma gestão pública extremamente instável, durante as seis décadas de existência do parque. Ela retoma, ao final, o destino do primeiro projeto, de 1954, do qual algumas pranchas originais pertencem atualmente ao acervo do MoMA. Embora não tenha conseguido realizar esse projeto, Burle Marx, de alguma forma, o perpetuou. 
De volta ao Rio de Janeiro, Márcia Regina Romeiro Chuva trata dos processos de patrimonialização do Parque do Flamengo, um projeto de Roberto Burle Marx e do arquiteto Affonso Eduardo Reidy tombado em 1965 pelo Instituto do Patrimônio Histórico e Artístico Nacional (lphan). A autora detém-se especificamente sobre as tensões que envolvem os jardins e o projeto arquitetônico do parque nos debates ocorridos no âmbito do Iphan no momento de seu tombamento e também nos que a eles se seguiram. A decisão de tombar o espaço foi tomada no contexto de profundas transformações urbanas sofridas pelo Rio de Janeiro, ocorridas quando a cidade ainda era a capital do país e, em seguida, sob o governo de Carlos Lacerda (19601965) e no período militar, a partir de 1964. Privilegiando uma abordagem centrada na questão do "direito à cidade", a autora lança luzes contundentes sobre os antagonismos existentes entre a preservação do patrimônio e a especulação imobiliária. E prolongando sua reflexão até as políticas patrimoniais recentes, Márcia Chuva as examina no contexto dos grandes eventos esportivos que ocorreram na cidade, desde os Jogos Panamericanos de 2007 até as Olimpíadas de 2016. Articula essa questão, por fim, com o papel desempenhado pelo Parque do Flamengo na decisão da Unesco, ocorrida em 2012, de conceder à "paisagem cultural" do Rio de Janeiro o título de Patrimônio Mundial.

Este conjunto de artigos pretende contribuir para a renovação, já em curso, relativa aos estudos de parques e jardins do Brasil, especialmente no que toca à superação das perspectivas formalistas que tanto marcaram esse campo de pesquisas. Essas últimas abordagens - ainda bem vivas - emanam de uma história do paisagismo que, até muito recentemente, era sobretudo concebida como uma extensão da história da arte. Este dossiê, deliberadamente interdisciplinar e voltado a questionamentos inovadores, traz à luz atores inesperados, técnicas pouco conhecidas e raramente estudadas ou, ainda, de modos pouco usuais de exercer a preservação patrimonial. Ele almeja ainda contribuir para o questionamento de práticas e paradigmas tão estabelecidos quanto impermeáveis a qualquer problematização.

Lembremos, por fim, que Fernanda Curi destacou claramente a procrastinação das autoridades públicas de São Paulo em implementar os sucessivos projetos de Burle Marx, privando assim a cidade de espaços complexos e de alta qualidade. A história recente do aterro do Flamengo, como relatado por Márcia Chuva, é outra demonstração da permeabilidade das autoridades públicas aos interesses privados pouco afeitos ao tombamento federal do parque e à sua inclusão no perímetro de proteção da Unesco em 2012. Da mesma forma, as iniciativas recentes da Prefeitura Municipal de São Paulo que têm por objetivo privatizar a gestão de todos os seus parques e jardins estão inscritas, sem qualquer contraste, numa história, no mínimo turbulenta, das práticas de valorização e de proteção desses patrimônios pouco conhecidos das cidades brasileiras - que este dossiê espera ter podido auxiliar em sua melhor compreensão. 


\section{REFERÊNCIAS}

ANDERSON, Elijah. The Cosmopolitan Canopy: Race and Civility in Everyday Life. Nova York; Londres: W.W. Norton \& Company, 2011.

BARTALINI, Vladimir. Parques públicos municipais de São Paulo: a ação da municipalidade no provimento de áreas verdes de recreação. Tese (doutorado) - Faculdade de Arquitetura e Urbanismo / Universidade de São Paulo, São Paulo, 1999.

BERIAC, Jean-Pierre. Auguste Glaziou, un paysagiste entre Bordeaux et Rio de Janeiro. Revue Archéologique de Bordeaux, Bordeaux, n. 103, p. 231-262, 2012.

CAVALCANTI, Lauro; EL-DAHDAH Farés. Roberto Burle Marx: a permanência do instável. Rio de Janeiro: Rocco. 2009.

CALVALCANTI, Lauro; EL-DAHDAH Farés; RAMBERT, Francis (org.). Roberto Burle Marx: la modernité du paysage. Paris: Cité de l'architecture et du patrimoine / Institut français d'architecture; Barcelone: Actar. 2011.

DOURADO, Guilherme Mazza. Belle Époque dos jardins. São Paulo: Ed. Senac, 2011.

HOFFMANN, Jens; NAHSON, Claudia J.. Roberto Burle Marx: Brazilian Modernist. Nova York: The Jewish Museum; New Haven: Yale University Press, 2016.

MACEDO, Silvio Soares. Quadro do paisagismo no Brasil. São Paulo: FAU-USP, 1999.

Paisagismo brasileiro na virada do século - 1990-2010. São Paulo: Edusp/Ed.

Unicamp, 2012.

MACEDO, Silvio Soares; SAKATA; Francine Gramacho. Parques urbanos no Brasil. São Paulo: Edusp/Impresa Oficial. 2002.

SEGAWA, Hugo. Ao amor do público: jardins no Brasil. São Paulo: FAPESP/Studio Nobel. 1996. 
TERRA, Carlos Gonçalves. Os jardins no Brasil no século XIX: Glaziou revisitado. Rio de Janeiro: EBA/UFRJ. 2000.

TERRA, Carlos Gonçalves. Exchange of Useful Plants between Brazil and England in the Second Half of the Nineteenth-Century: Glaziou and the Botanists of the Royal Botanic Gardens. Kew Bulletin: Official Journal of the Royal Botanic Gardens, Kew, v. 70, n. 1, p. 1-10, 2015.

ROBBA, Fabio; MACEDO, Silvio Soares. Praças brasileiras. São Paulo: Edusp/Imprensa Oficial, 2002.

SCOBEY, David. Anatomy of the Promenade: The Politics of Bourgeois Sociability in Nineteenth-Century New York. Social History, v. 17, n. 2, p. 203-227, 1992.

All the contents of this journal, except where otherwise noted, is licensed under a Creative Commons Attribution License

\section{(cc) BY}

